\title{
ИММУНОЛОГИЧЕСКАЯ И АУТОИММУННАЯ РЕАКТИВНОСТЬ БОЛЬНЫХ ДЕТЕЙ С ИНСУЛЬТОМ
}

\author{
*Касимова Н.С., Маджидова Ё.Н., Алиджанова Д.А., Юсупова Д.М. \\ Кафедра неврологии, детской неврологии и медицинской генетики Ташкентского \\ Педиатрического Медицинского Института, Ташкент, Узбекистан
}

\begin{abstract}
В основу исследования были положены данные изучения иммунологических показателей у 28 детей с инсультом в разные периоды заболевания. Так было установлено, что у детей в остром периоде заболевания наблюдается нарушение цитокинового баланса в сторону гиперпродукции провоспалительных цитокинов и сопровождается избыточными симптомами воспаления, что является центральным звеном патогенеза данной патологии. Уровень аутоантител к эндотелию сосудов (ANCA) был в 3 раза выше контрольных значений, что свидетельствует о выраженном воспалении интимы сосудов. У детей в позднем восстановительном периоде наблюдается нормализация цитокинового статуса на фоне снижения воспаления интимы сосудов.

Ключевые слова: детский инсульт, иммунологическая реактивность.
\end{abstract}

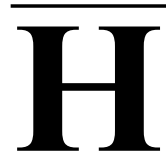

есмотря на высокую значимость проблемы детского инсульта с демографической и социально-экономической точек зрения, эпидемиологические исследования инсульта в детской популяции часто локальны по поставленным задачам, очень дороги, поэтому недостаточно всесторонни и проводятся на ограниченной территории планеты $[3,9]$. Как следствие, возникают значительные сложности в дальнейшей разработке основ интегральной популяционной стратегии цереброваскулярных заболеваний у детей и подростков [10].

В настоящее время не вызывает сомнения, что наряду с другими факторами, в патогенезе инсультов важная роль принадлежит иммунологическим механизмам $[1,3,6]$. Выявлено участие целого ряда иммунных механизмов: аутоиммунная агрессия, апоптоз, локальная воспалительная реакция с участием цитокинов.

Активность клеточных и гуморальных механизмов при инсульте определяется системой цитокинов. Известно, что дисбаланс про(Th1) и противовоспалительных (Th2) цитокинов играет важную роль в иммунопатогенезе нарушений мозгового кровообращения. Синтезируясь в очаге воспаления, цитокины воздействуют практически на все клетки, участвующие в развитии воспаления, включая нейтрофильные гранулоциты, макрофаги, фибробласты, клетки эндотелия и эпителия, а также Т- и В-лимфоциты. В экспериментальных исследованиях выявлено повы*e-mail: dr.ibragimova@gmail.com шение концентрации провоспалительных цитокинов (интерлейкинов $1,6,8$, фактора некроза опухоли альфа) в условиях фокальной ишемии мозга, что сопровождается развитием локального воспаления в очаге ишемического повреждения. Уровни провоспалительных цитокинов остаются достоверно повышенными в течение нескольких дней после развития инсульта, что свидетельствует об интенсивности воспалительных реакций и их роли в процессах повреждения ткани мозга [7].

Реакция антиген-антитело, развивающаяся при нарушении мозгового кровообращения, охватывает не только сосудистую стенку, но распространяется непосредственно на ткань мозга, вовлекая в процесс преимущественно сосудистые ножки астроцитарной глии [5]. Являясь единственным иммунокомпетентным компартментом в центральной нервной системе, микроглия участвует во всех реакциях ткани мозга на ишемию. Вследствие этого развитие этой реакции сказывается на всех известных механизмах ауторегуляции мозгового кровотока: воздействие высвобожденных при изменении внутрисосудистого давления гистамина и других биологически активных веществ на сократительный аппарат гладких мышц сосудов и развитие эффекта Остроумова-Бейлиса; сдвиг гомеостаза и изменения $\mathrm{pO}_{2}, \mathrm{pCO}_{2}, \mathrm{pH}$; изменение нейрорегуляции мозгового кровотока; десквамация эндотелия сосудов; повышение вязкости крови и агрегационной способности эритроцитов [4]. 
В результате происходящих иммунобиохимических процессов происходит запуск механизмов вторичного повреждения, среди которых наиболее важное значение имеют реакции аутоиммунной агрессии, приводящие к локальному воспалению и апоптозу $[2,8]$.

При исследовании уровня криоглобулинов у больных инсультом, было показано, что криоглобулинемия при инсульте имеет не только диагностическое значение, но и является серьезным патогенетическим фактором, участвуя в развитии микроциркуляторных и гемореологических нарушений в остром периоде заболевания, достоверно увеличивая вязкость крови и приводя к развитию иммунокомплексного эндоваскулита мелких сосудов головного мозга в очаге ишемии [8].

Однако, не смотря на имеющиеся в литературе данные, по изучению иммунного и аутоиммунного статуса при инсультах, фрагментарны и противоречивы, а исследования у детского контингента больных весьма малочисленны. Остаются нерешенными вопросы иммунопатогенеза инсультов, в частности, вопросы иммунорегуляции и роли аутоиммунных нарушений в формировании исходов заболевания.

В связи с вышеизложенным целью данной работы явилось изучение содержание показателей цитокинового спектра (IL-1 $\beta$, IL-10) и аутоиммунной реактивности в разные периоды заболевания (в острый период и в позднем восстановительном периоде) инсультом у детей.

Материалы и методы исследования: в основу исследования положены данные клиникоиммунологического обследования 28 детей с инсультом в разные периоды заболевания (в острый период - 12 детей, и в позднем восстановительном периоде - 16 детей). Возрастная градация детей составила от рождения до 3 лет. Контрольную группу составили 10 здоровых детей того же возраста.

Диагноз устанавливали по результатам клинико-неврологических и инструментальных исследований (НСГ, компьютерная и магнитно-резонансная томография).
На основании проведения анамнестического анализа были выявлены такие факторы риска развития ДИ у детей раннего возраста в антенатальном периоде, как анемия (70,5\%), гестозами $(52,3 \%)$, преэклампсия $(34,1 \%)$, заболевания почек $(31,8 \%)$ у матери и патологии течения беременности. Среди перинатальных факторов риска развития у новорожденных ДИ (доля неблагоприятных исходов беременности составила 54,5\%) наблюдались срочное кесарево сечение $(15,9 \%)$, травматические роды с применением щипцов и вакуумэкстракции $(13,6 \%)$.

Анализ факторов риска показал роль инфекционного заболевания верхних дыхательных путей, легкой травмы головы (ушиба мягких тканей головы), повышенной физической нагрузки в развитии инсульта у детей раннего возраста.

В неврологическом статусе у детей раннего возраста в остром периоде чаще выявлялись синдромы: церебральной депрессии, церебральной возбудимости, судорожный синдром и ликворо-сосудистых дистензий, тогда как при ишемическом типе достоверно чаще наблюдались судорожный синдром и другие нарушения мышечного тонуса.

У детей поздний восстановительный период проявляется поражением ЧМН с пирамидными знаками, задержкой моторного, когнитивного и психоречевого развития.

Уровень провоспалительных и противовоспалительных цитокинов (IL-1, IL-10) проводились методом иммуноферментного анализа с использованием коммерческих тестсистем "Вектор-Бест", Россия. Эти тест-системы основаны на сэндвич-методе твердофазного иммуноферментного анализа с применением пероксидазы хрена в качестве идикаторного фермента.

Для определения ANCA использовали иммунофлуоресцентный метод. Принцип метода: в лунках планшета с предварительно сорбированными антигенными компонентами, после добавления разведенных контрольной сыворотки и анализируемых проб сыворотки крови и их инкубации устанавливается равновесие между связанными и свободными ан- 
тителами к соответствующим антигенам. После удаления содержимого лунок и внесения в них раствора конъюгата кроличьих антител к IgG человека с пероксидазой хрена происходит сорбция молекул конъюгата в количестве, прямо пропорциональном количеству связавшихся аутоантител. После удаления избытка несвязанного конъюгата проводится ферментативная реакция пероксидазы с перекисью водорода в присутствии хромогена (тетераметилбензидина; ТМБ) для определения активности пероксидазы. После остановки пероксидазной реакции стоп-реагентом оценка результатов проводится фотометрически при длине волны 450 нм. Далее проводится расчет результатов относительной иммунореактивности определяемых антител в пробах (у.е.).

Полученные данные статистически обрабатывались на персональном компьютере по программам, разработанным в пакете EXCEL с использованием библиотеки статистических функций с вычислением среднеарифметической (М), среднего квадратичного отклонения $(\sigma)$, стандартной ошибки $(\mathrm{m})$, относительных величин (частота, \%), критерий Стьюдента (t) с вычислением вероятности ошибки (p). Различия средних величин считали достоверными при уровне значимости $\mathrm{p}<0,05$. С учетом указаний по статистической обработке данных клинических и лабораторных исследований.

Результаты и их обсуждение. В результате проведенных исследований по изучению содержания в сыворотке крови IL-1 $\beta$, IL-10 и ANCA у больных детей с инсультом получены следующие результаты.
Важным инициирующим воспаление цитокином является IL-1 $\beta$. В группе больных выявлено достоверное повышение основного провоспалительного цитокина, поддерживающего воспаление. В этом случае не всегда IL-1 $\beta$ играет положительную роль в течении заболевания. Нарушение цитокинового баланса в сторону гиперпродукции IL-1 $\beta$ сопровождается избыточными симптомами воспаления, а порой является центральным звеном патогенеза воспаления, как на местном уровне, так и на системном.

Уровень ИЛ-1 $\beta$ у детей с детским инсультом был достоверно повышенным и составил в среднем 103,3 $\pm 4,7$ пг/мЛ ( $<<0,001)$. Исходя из полученных данных, мы предполагаем наличие определенной зависимости уровня продукции ИЛ-1 $\beta$ от характера патологического процесса, о чем свидетельствует довольно высокий уровень его секреции в группе больных (примерно в 5 раз).

Целым рядом исследований доказано, что важное значение в патогенезе поражений головного мозга отводится ИЛ-10. Данный цитокин продуцируется ТХ2 типа клетками, Влимфоцитами, моноцитами, макрофагами и тучными клетками. Считают, что механизмы его действия являются противовоспалительный, иммуномодулирующий, иммуносупрессивный. Исходя из этих данных мы видим, что ИЛ-10 в данном конкретном случае проявил себя как противовоспалительный и иммуносупрессивный белок. В нашем исследовании уровень IL-10 в общей группе больных был несколько снижен, однако разница показателей была недостоверна ( $\mathrm{p}>0,001)$ по сравнению с контрольной группой (табл.1).

\section{Содержание цитокинов и аутомаркеров в сыворотке крови у больных, $(\mathrm{M} \pm \mathrm{m})$}

\begin{tabular}{|l|c|c|}
\hline Показатели & Контрольная группа & Больные инсультом \\
\hline ИЛ-1 $\beta$, пг/мл & $29,9 \pm 1,8$ & $103,3 \pm 4,7^{*}$ \\
\hline ИЛ-10, пг/мл & $17,2 \pm 2,7$ & $12,9 \pm 1,0$ \\
\hline ANCA, усл.ед. & $0,501 \pm 0,024$ & $0,962 \pm 0,056$ \\
\hline
\end{tabular}

Примечание: * - значения достоверны по сравнению с контрольной группой. 
При рассмотрении показателей аутоиммунной реактивности, видно, что уровень аутоантител к эндотелию сосудов (ANCA) был значительно выше и составил 0,962 $\pm 0,056$ у.д,, что примерно в 3 раза выше чем в контрольной группе, и говорит о выраженном воспалительном процессе в интиме сосудов.

На следующем этапе нашего исследования мы рассматривали показатели цитокинового статуса (IL-1 $\beta$, IL-10) и аутоиммунной реактивности в зависимости от периода заболевания (острый период и поздний восстановительный период) (табл.2).

\section{Содержание цитокинов и аутомаркеров в сыворотке крови у больных, $(\mathrm{M} \pm m)$}

\begin{tabular}{|l|c|c|c|}
\hline Показатели & Контрольная & \multicolumn{2}{|c|}{ Дети с детским инсультом } \\
\cline { 3 - 4 } & группа $(\mathrm{n}=10)$ & $\begin{array}{c}\text { Острый период } \\
(\mathrm{n}=12)\end{array}$ & $\begin{array}{c}\text { Поздний } \\
\text { восстановительный } \\
(\mathrm{n}=16)\end{array}$ \\
\hline ИЛ-1 $\beta$, пг/мл & $29,9 \pm 1,8$ & $119,4 \pm 4,4^{*}$ & $81,5 \pm 4,0^{*}$ \\
\hline ИЛ-10, пг/мл & $17,2 \pm 2,7$ & $9,9 \pm 1,2^{*}$ & $16,3 \pm 0,8$ \\
\hline АNСА, усл.ед. & $0,501 \pm 0,024$ & $1,134 \pm 0,041^{*}$ & $0,626 \pm 0,051$ \\
\hline
\end{tabular}

Примечание: * - значения достоверны по сравнению с контрольной группой.

Как видно из полученных данных у детей с инсультом в остром периоде заболевания отмечается достоверное повышение ИЛ-1 $\beta$ и ANCA на фоне снижения ИЛ-10. В позднем восстановительном периоде содержание ИЛ10 и ANCA достигает значений контрольной группы, что нельзя сказать про ИЛ- $1 \beta$ его показатели в позднем восстановительном периоде имели тенденцию к снижению, но также были достоверно высокие $(\mathrm{p}<0,05)$.

Полученные результаты показали, что если в позднем восстановительном периоде показатели иммунной и аутоиммунной реактивности организма сохраняют изменения, свойственные для острого периода болезни, это является прогностически неблагоприятным критерием при прогнозе заболевания.

\section{ЛИТЕРАТУРА}

1. Ado A.D. O vzaimodeystvii nervnoy i immunokompetentnoy sistem // Vestnik RAMN. 1993- №7. - pp.48-51.

2. Akimov G. A., SHamrey R.K. Autoimmunnie processi v patogeneze sosudistih zabolevaniy golovnogo mozga. M.: Sovetskaya medicina, 1983- pp.72-75.

3. Dzyak L.A., Curkalenko E.S. Insult u molodih pacientov // Zdorov'ya Ukraïni, 2009- 5/1. -pp.12-15.

4. Krijanovskiy G.N., Magaeva S.V, Makarov S.V., Sepiashvili R.I. Neyroimmunopatologiya. Rukovodstvo. M.: izd-vo NII obщеy patologii i patofiziologii, 2003. p 438
Заключение. Таким образом, проведенное исследование выявило участие иммунных реакций и вызываемого ими локального воспаления в патогенезе инсульта и формировании инфарктных изменений в ткани мозга человека, продемонстрировало значимость не только избыточного выброса провоспалительных цитокинов, но и дефицита защитных противовоспалительных цитокинов в развитии воспалительного ответа.

У детей с инсультом при оценке клинического течения и назначения терапии следует учитывать состояние иммунной и аутоиммунной реактивности организма.

Обнаружение высокого уровня ИЛ-1 $\beta$ и ANCA указывает на неблагоприятный прогноз в отношении течения заболевания.

5. Poletaev A.B. Novie podhodi k rannemu viyavleniyu patologicheskih izmeneniy $\mathrm{v}$ organizme cheloveka: Metodicheskie rekomendacii dlya vrachey. - Moskva, 2009, 58 p.

6. Barone F.C., Feuerstein G.Z. Inflammatory mediators and stroke: New opportunities for novel therapeutics // J. Cereb. Blood. Flow. Metab. 1999-Vol.19. -P.819-834.

7. Liu T., Clark R.K., McDonnell P.C., Young P.R., White R.F., Barone F.C., Feuerstein G.F. Tumour necrosis factor a expression in ischemic neurons // Stroke. 1994, 
-Vol.25. -P.1481-1488

8. Meisel C., Schwab J.M., Prass K., Meisel A., Dirnagl U. Central nervous system injury-induced immune deficiency syndrome // Nat. Rev. 2005-Vol.6. -P.775-786.

9. Rafay M.F., Cortez M.A., de Veber G.A. et al. Predictive value of clinical and EEG features in the diagno- sis of stroke and hypoxic ischemic encephalopathy in neonates with seizures // Stroke. 2009-. - 40. - p. 2402 -2405. 10. Simchen M.J., Goldstein G., Lubetsky A. et al. Factor $v$ Leiden and antiphospholipid antibodies in either mothers or infants increase the risk for perinatal arterial ischemic stroke // Stroke. 2009, -40. -p.65-69.

\title{
XÜLASə
}

\section{INSULTLA XəSTə UŞAQLARDA İMMUNOLOJİ Və AUTOIMMUN REAKTIVLIKK}

\author{
Kasimova N.S., Madjidova Yo.N., Alidjanova D.A., Yusupova D.M. \\ Daşkənt pediatrik tibb institutu, nevrologiya, uşaq nevrologiyası vo tibbi genetika kafedrası, \\ Daşkənd, Özbəkistan
}

Tədqiqata insultlu 28 uşağın, xəstəliyin müxtəlif dövrlərində immunoloji göstəriciləri daxil edilmişdir. Təyin edilmişdir ki, uşaqlarda insultun kəskin dövründə iltihab sitokinlərinin hiperproduksiyası istiqamətində sitokin balansının pozulması müşahidə edilir və iltihabın qabarıq simptomları ilə müşaiyət olunur ki, bu da təqdim edilmiş patologiyanın patogenezinin mərkəzi bəndi təşkil edir. Damar endotelinə qarşı yaranan autoanticisimlərin (ANCA) səviyyəsi kontrol göstəricilərdən 3 dəfə yüksək olmuşdur ki, bu da damarların intima qişasının qabarıq iltihabına dəlalət edir. Gecikmiş bərpa dövründə olan uşaqlarda damarların intima qişasının iltihabının azalması fonunda sitokin statusunun normallaşması müşahidə edilir

Açar sözlər: uşaqlarda insult, immjnoloji reaktivlik.

\section{SUMMARY}

\section{IMMUNOLOGICAL AND AUTOIMMUNE REACTIVITY OF CHILDREN WITH STROKE}

\author{
Kasimova N.S., Madjidova Yo.N., Alidjanova D.A., Yusupova D.M. \\ Department of "Neurology, Child neurology and medical genetic" of Tashkent Pediatric \\ Medical Institute, Tashkent, Uzbekistan
}

The study was based on data study of immunological parameters in 28 children with stroke in different periods of the disease. Thus, it was found that in children with acute disease there is a violation of the cytokine balance in favor of pro-inflammatory cytokine overproduction and excessive symptoms accompanied by inflammation, which is central to the pathogenesis of this disease. The level of autoantibodies to the vascular endothelium (ANCA) was 3 times higher than the control values, indicating that a pronounced inflammation of the intima of blood vessels. The children in the late recovery period are observed normalization of cytokine status due to lower inflammation of the intimae of blood vessels.

Keywords: children's stroke, immunologic reactivity.

Redaksiyaya daxil olub: 07.06.2016

Çapa tövsiya olunub: 28.06 .2016

Rayçi: prof. R.K.Şiraliyeva 